\title{
Anti-Hyperprolactinemic Effect of Formula Malt Decoction, a Chinese Herbal Cocktail
}

\author{
Ming-xia $\mathrm{Li}^{1}$, Hong $\mathrm{Liu}^{2}$, Yan $\mathrm{Li}^{3}$, Fei Wang ${ }^{4}$, Pei-rong Zhang ${ }^{5}$ and Ping Zang ${ }^{6 *}$ \\ ${ }^{1}$ College of Nursing, Shandong University of Traditional Chinese Medicine, Jinan, 250355, ${ }^{2}$ Department of Business \\ Development, Affiliated Hospital of Weifang Medical University, ${ }^{3}$ ICU, Weifang Traditional Chinese Hospital, ${ }^{4}$ Department of \\ Neurosurgery, ${ }^{5}$ ICU, ${ }^{6}$ Public Health Management Office, Affiliated Hospital of Weifang Medical University, Weifang, 261031 , \\ Shandong, China
}

*For correspondence: Email: zangping133494@163.com; Tel: +86 05368536155

Received: 29 September 2014

Revised accepted: 17 January 2015

\begin{abstract}
Purpose: To investigate the anti-hyperprolactinemic activity of Formula Malt Decoction (FMD), a Chinese herbal mixture.

Methods: The effect of FMD on serum prolactin (PRL), estradiol (E2), progesterone (PGN), follicle stimulating hormone (FSH) and luteinizing hormone (LH) levels were investigated in hyperprolactinemic (hyperPRL) rats. The effect of FMD on PRL secretion, dopamine D2 receptor and dopamine transporters (DAT) were studied in MMQ cells derived from rat pituitary adenoma cells, GH3 cells derived from rat pituitary lactotropic tumoral cells and PC12 cells from rat pheochromocytoma, respectively.

Results: Compared with the model group, a high dose of FMD (11.6 g/kg body weight) and medium dose of FMD (5.8 g/kg body weight) reduced PRL level of hyperPRL rats effectively. In MMQ cells, treatment with $5 \mathrm{mg} / \mathrm{ml}$ FMD $(p<0.01)$ or $10 \mathrm{mg} / \mathrm{mL}$ FMD $(p<0.01)$ significantly suppressed PRL secretion and synthesis at $24 \mathrm{~h}$ compared with controls $(p<0.01)$. Consistent with D2- action, FMD did not affect PRL in rat pituitary lactotropic tumor-derived $G H 3$ cells that lack the $D 2$ receptor expression compared with controls, but $8 \mathrm{mg} / \mathrm{mL} F M D$ significantly increased the expression of D2 receptors $(p<$ $0.01)$ and DAT $(p<0.01)$ in PC12 cells.

Conclusion: FMD shows anti-hyperprolactinemia activity via dopamine $D 2$ receptor.
\end{abstract}

Keywords: Formula Malt Decoction, Hyperprolactinemia, Dopamine D2 Receptor, Prolactin, Estradiol, Progesterone follicle stimulating hormone, Luteinizing hormone

Tropical Journal of Pharmaceutical Research is indexed by Science Citation Index (SciSearch), Scopus, International Pharmaceutical Abstract, Chemical Abstracts, Embase, Index Copernicus, EBSCO, African Index Medicus, JournalSeek, Journal Citation Reports/Science Edition, Directory of Open Access Journals (DOAJ), African Journal Online, Bioline International, Open-J-Gate and Pharmacy Abstracts

\section{INTRODUCTION}

Hyperprolactinemia, is one of the most common endocrine disorders of the hypothalamuspituitary axis (PRL > $25 \mathrm{ng} / \mathrm{mL}$ ) in young women. It is associated with galactorrhea and ovulatory dysfunction that result in menstrual irregularities and bareness [1]. HyperPRL can occur at any age, and the prevalence varies from $0.4 \%$ in the normal adult population to as high as $9-17 \%$ in women with menstrual problems such as amenorrhea and polycystic ovarian syndrome $[2,3]$. Synthetic drugs are used in treating them, but they always bring many side effects such as menstrual disorder and the relapse rate is very high. It has been reported that $12 \%$ patients cannot endure bromocriptine, which is a widely used synthetic drug in clinical practice [4].

Empirical evidence suggests that many herbal medicines possess therapeutic potential for alleviating hyperPRL symptoms [5]. Formula Malt 
Decoction is widely used in China for the treatment of hyperprolactinemia and has produced a favorable effect. Formula Malt Decoction (FMD) is composed of $60 \mathrm{~g}$ Mai Ya (Fructus Hordei Germinatus), Xia Ku Cao (Prunella vulgaris L.) $15 \mathrm{~g}$, Chai Hu (Bupleurum chinense DC.), Dang Gui (Angelica sinensis), and $10 \mathrm{~g}$ Dan Shen (Salvia miltiorrhiza Bge.). 10 g Fructus Hordei Germinatus, the main herb of FMD, and its extract decreases prolactin levels in hyperPRL mice $[6,7]$.

Most conventional anti-hyper PRL agents reduce PRL secretion through D2 receptor in the hypothalamic-neuroendocrine dopaminergic system [8]. Other sex steroids are also involved in the pathophysiology of hyperPRL [9]. In this study, we investigated the effects of FMD on serum E2, P, FSH and LH levels in hyper PRL rats; as well as its effect on D2 receptor- and DAT-mediated responses and PRL secretion in cell- culture systems. MMQ cell derived from rat pituitary adenoma cells, GH3 cell derived from rat pituitary lactotropic tumoral cells and PC12 cells from rat pheochromocytoma were used.

\section{EXPERIMENTAL}

\section{Preparation of FMD}

The dried and crushed herbs of FMD were mixed, and decocted with $1100 \mathrm{ml}$ water twice, $45 \mathrm{~min}$ for each. Then the filterate was mixed and concentrated into $200 \mathrm{ml}$ liquor of FMD. After being filtered through a $0.2 \mu \mathrm{m}$ filter, the liquor of FMD was used for in vitro and in vivo experiments.

\section{In vivo experiments in animal model of hyperPRL}

Female Wistar rats weighing 200 - 220 g were obtained from Shandong Center for Disease Control and Prevention, Jinan, Shandong. The animals had free access to feed and water, and were allowed to acclimatize for at least one week before use. All experiments were approved by the Animal Care and Use Committee of Shandong University of Traditional Chinese Medicine (Approval reference NO. 20130912) and was carried out in compliance with the Directive 2010/63/EU on the handling of animals used for scientific purposes [10].

Rats were given intraperitoneal (i.p.) metoclopramide (MCP, $150 \mathrm{mg} / \mathrm{kg}$ body weight daily) for 10 days to prepare the model of hyper PRL [11]. 60 rats were randomly divided into six groups of ten rats: control, model group, bromocriptine-treated group, high-dose FMD- treated (11.6 g/kg body weight) group, middledose FMD-treated (5.8 $\mathrm{g} / \mathrm{kg}$ body weight) group and low-dose FMD-treated $(2.9 \mathrm{~g} / \mathrm{kg}$ body weight) group. Each dose was dissolved in $2 \mathrm{ml}$ water, and administered by gavage. The dosage was calculated from the human clinical dosage of FDM based on body surface area. Control and untreated model rats received $2 \mathrm{~mL}$ of saline water. All the mice received treatment for 30 days. After finishing the treatment serum PRL, $\mathrm{E} 2, \mathrm{PGN}, \mathrm{FSH}$ and $\mathrm{LH}$ levels of the rats were measured by ELISA.

\section{In vitro experiments in culture cells}

\section{Cell lines and culture}

MMQ cell which is derived from rat pituitary adenoma cells, GH3 cell (derived from rat pituitary lactotropic tumoral cells) and PC12 cell (derived from rat pituitary lactotropic tumor) were used in the in vitro experiments. Dose-dependent and time-course responses of PRL secretion and synthesis to FMD treatment were evaluated in MMQ cell line. Effects of FMD on dopamine D2 receptor and DAT were further examined in PC12 cells. MMQ, GH3 and PC12 cell lines were cultured in $65 \mathrm{~cm}^{2}$ flask, supplemented with $5 \%$ fetal calf serum (FBS), $11 \%$ heat-inactivated horse serum (HS), penicillin (100 IU/ml), and streptomycin $(100 \mu \mathrm{g} / \mathrm{mL})$ under a humidified atmosphere containing $5 \% \mathrm{CO}_{2}$ at $37{ }^{\circ} \mathrm{C}$. The culture medium was replaced with fresh medium every two days. When the density reached $75 \%$ confluence, culture cells were transferred to 35 mm-diameter 6-well plates for experimental treatment.

MMQ cells were treated with FMD at concentrations of $1-8 \mathrm{mg} / \mathrm{mL}$ for $12-48 \mathrm{~h}$. At different incubation time points, the culture medium was collected for measuring PRL secretion. Cells were collected for determining cellular PRL expression. The optimal concentrations and treatment duration were then determined for subsequent experiments. GH3 and PC12 cells were treated with FMD at effective concentrations that had been determined in MMQ cells for $24 \mathrm{~h}$. The GH3 cells and medium were collected for the measurement of $\mathrm{PRL}$ secretion and expression respectively. The PC12 cells were collected for detecting D2 receptor and DAT expressions.

\section{Biochemical analysis}

\section{Hormone assays}

PRL concentrations in the culture medium collected from MMQ and $\mathrm{GH} 3$ cells as well as 
serum PRL, E2, PGN, FSH and LH concentrations of rat were measured using ELISA kits (Wuhan boster Biological Engineering Co, Ltd).

\section{Western blotting}

Expressions of intracellular PRL in $\mathrm{MMQ}$ and GH3 cells as well as D2 receptors and DAT in PC12 cells were determined by western blotting. The cell proteins were extracted and the concentration was determined by Bradford method. Proteins were separated by a $10 \%$ SDS-PAGE gel and transferred electrophoretic ally onto nitrocellulose membranes (Bio Basic, Inc). Immune detection was performed with the primary antibodies against $\mathrm{PRL}, \mathrm{D} 2$ receptors, and DAT at a dilution of $1: 1000$ at $4{ }^{\circ} \mathrm{C}$ overnight, followed by co-incubation with horseradish peroxidase (HRP)-conjugated secondary antibodies for $30 \mathrm{~min}$ at room temperature. The primary antibody was served against glyceraldehyde 3-phosphate dehydrogenase (GAPDH) as a standard control for protein loading. The chemiluminescence was determined by ECL detection kits (Shang hai Best Bio, China). The intensity of protein bands was quantified by scanning densitometry using Quantity One 4.5.0 software.

\section{Statistical analysis}

One- or two-way analysis of variance (ANOVA) was used to detect statistical significance, followed by post-hoc multiple comparisons (Student-Newman-Keuls method). Data are expressed as mean \pm SEM. Statistical significance was defined as $p<0.05$.

\section{RESULTS}

\section{Effect of FMD on sex hormones in rat model of hyperPRL}

Compared with control group, serum PRL level of hyperPRL model rats increased significantly $(p<$
0.01). Serum E2, PGN and FSH and LH ( $p<$ $0.05)$ levels of hyperPRL model rats decreased significantly $(p<0.01)$ after treatment with intraperitoneal metoclopramide.

The increased PRL level was significantly attenuated by treatment with $0.6 \mathrm{mg} / \mathrm{kg}$ bromocriptine and 5.8 or $11.6 \mathrm{~g} / \mathrm{kg}$ FMD after 30 days $(p<0.01)$ compared with model group. Compared with model group, rat serum E2 level decreased $(p<0.01)$, and serum PGN, FSH and LH levels increased $(p<0.05)$ effectively in bromocriptine-treated group. Compared with model group, rat serum E2 level decreased ( $p<$ 0.01), and serum $\mathrm{P}, \mathrm{FSH}$ and $\mathrm{LH}$ levels increased $(p<0.05)$ significantly treated by highdose FMD (Table 1).

\section{Suppression of hyperactive PRL in MMQ and GH3 cells by FMD}

Two-way ANOVA analysis revealed a significant interaction between time course and treatment dose $(F=2.226, p=0.048)$. Post-hoc multiple comparison further revealed that 1 and 10 $\mathrm{mg} / \mathrm{mL}$ FMD treatment for 24 and $36 \mathrm{~h}$, but not 12 and $48 \mathrm{~h}$, produced significant suppression of $\mathrm{PRL}$ concentrations in the MMQ culture medium compared with controls $(0 \mathrm{mg} / \mathrm{mL})(p<0.006)$ (Fig. 1A). $24 \mathrm{~h}$ were then chosen.

FMD treatment for $24 \mathrm{~h}$ also yielded a significant suppression of $M M Q$ cellular PRL expression in a dose-dependent manner $(F=28.135, p<$ 0.001). Compared to controls, the significant suppression was observed in the higher two concentrations (5 and $10 \mathrm{mg} / \mathrm{mL})(p<0.003)$ (Fig. 1B). The same concentrations did not produce the significant effects on the medium concentration $(F=2.535, p=0.115)$ and the cellular expression ( $F=0.267, p=0.862)$ in $\mathrm{GH} 3$ cells (Fig. 2).

Table 1: Effect of FMD on sex hormones in hyperPRL rats

\begin{tabular}{llllll}
\hline Group & $\begin{array}{c}\text { PRL } \\
(\mathbf{p g} / \mathbf{m L})\end{array}$ & $\begin{array}{c}\text { E2 } \\
(\mathbf{p m o l} / \mathbf{L})\end{array}$ & $\begin{array}{c}\mathbf{P} \\
(\mathbf{n g} / \mathbf{m L})\end{array}$ & $\begin{array}{c}\text { FSH } \\
(\mathbf{I U} / \mathbf{L})\end{array}$ & $\begin{array}{c}\text { LH } \\
(\mathbf{m l U} / \mathbf{m L})\end{array}$ \\
\hline Control & $218.54 \pm 6.52$ & $3.59 \pm 0.32$ & $1.21 \pm 0.05$ & $0.97 \pm 0.06$ & $1.81 \pm 0.13$ \\
Model & $432.14 \pm 35.57^{* *}$ & $1.36 \pm 0.18^{* *}$ & $0.55 \pm 0.15^{* *}$ & $0.36 \pm 0.04^{* *}$ & $0.97 \pm 0.06^{*}$ \\
Bromocriptine & $225.69 \pm 11.70^{\Delta}$ & $2.56 \pm 0.26 \Delta \Delta$ & $0.73 \pm 0.03^{\Delta}$ & $0.71 \pm 0.02^{\Delta}$ & $1.62 \pm 0.05^{\Delta}$ \\
FMD-H & $226.15 \pm 11.51 \Delta$ & $2.55 \pm 0.15 \Delta \Delta$ & $0.86 \pm 0.05^{\Delta}$ & $0.62 \pm 0.02 \Delta$ & $1.71 \pm 0.21 \Delta$ \\
FMD-M & $251.62 \pm 14.63 \Delta$ & $2.34 \pm 0.38 \Delta$ & $0.81 \pm 0.06 \Delta$ & $0.67 \pm 0.03 \Delta$ & $1.58 \pm 0.04 \Delta$ \\
FMD-L & $320.26 \pm 47.22$ & $1.86 \pm 0.46$ & $0.54 \pm 0.11$ & $0.53 \pm 0.07$ & $1.02 \pm 0.12$ \\
\hline
\end{tabular}

Data are expressed as mean \pm SEM $(n=10)$ and analyzed using one-way ANOVA. ${ }^{*} p<0.05$ and ${ }^{* *} p<0.01$ versus control group; $\Delta p<0.05$ and $\Delta \Delta p<0.01$ versus model group. Key: FMD-H = high-dose FMD; FMD-M = medium-dose FMD; and FMD-L = low-dose FMD 


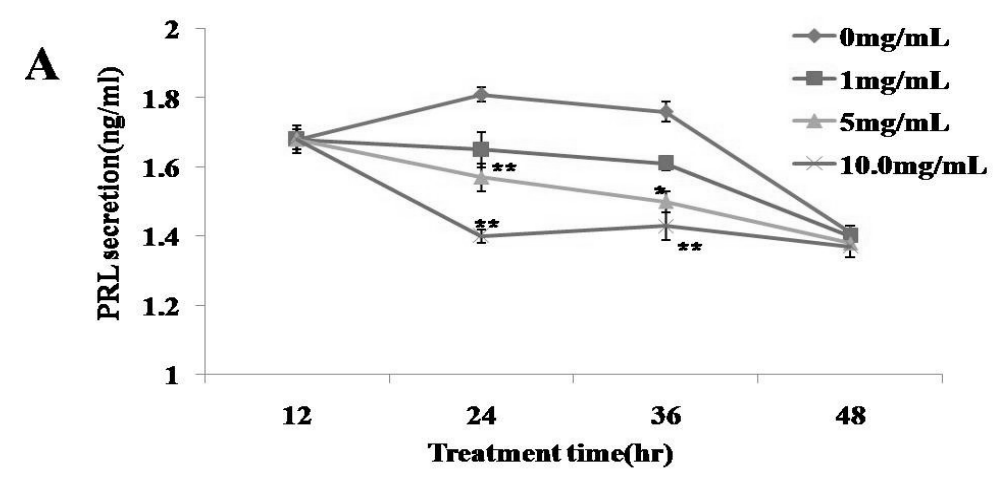

B

PRI.

GAPDH

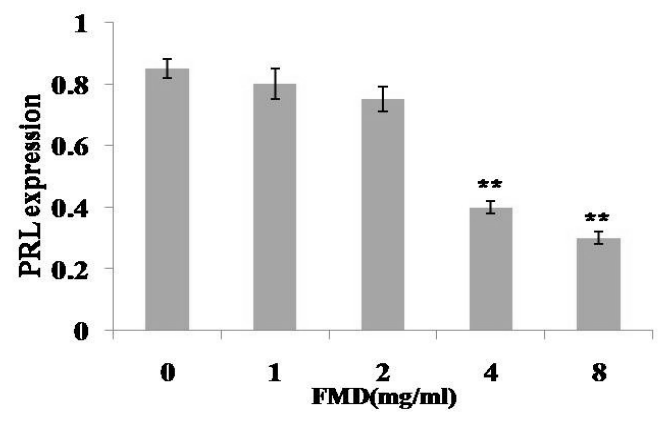

Fig 1: Time-course and dose-dependent effect of FMD in suppressing PRL secretion (A), and dose-dependent effect of FMD in inhibiting intracellular PRL expression (B) in MMQ cells. For the intracellular PRL expression, the cells were treated with different concentrations of FMD for $24 \mathrm{~h}$. Data are expressed as mean \pm SEM $(n=3)$ and analyzed using one- or two-way ANOVA; ${ }^{*} p<0.05$ and ${ }^{* *} p<0.01$ versus $0 \mathrm{mg} / \mathrm{mL}$ group
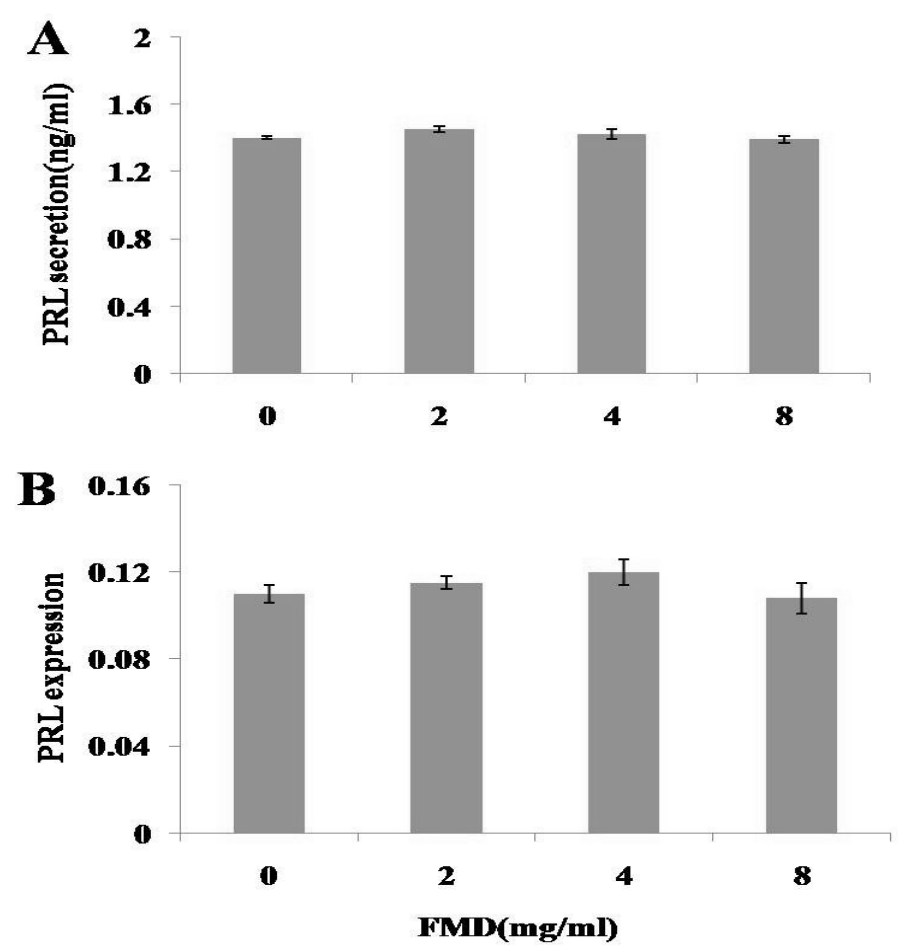

Fig 2: Effect of $24 \mathrm{~h}$ FMD treatment on $P R L$ secretion $(A)$ and synthesis $(B)$ in $G H 3$ cells. Data are expressed as mean \pm SEM $(n=3)$ and analyzed using one-way ANOVA. No significant differences were found in any multiple comparisons 


\section{Enhancement of dopamine expression in PC12 cells by FMD}

PC12 cells were treated with $2-8 \mathrm{mg} / \mathrm{mL}$ concentrations of FMD for $24 \mathrm{~h}$. One-way ANOVA revealed that FMD increased the expression of D2 receptors significantly $(F=$ $6.147, p=0.004)$ and DAT $(F=5.715, p=0.013)$ (Fig. 3). Multiple comparisons further exhibited that significant effects were attributed to concentrations of $4 \mathrm{mg} / \mathrm{ml}$ and $8 \mathrm{mg} / \mathrm{ml}$ compared to controls for D2 receptors ( $p<$ $0.013)$ and DAT $(p<0.029)$.

\section{DISCUSSION}

MMQ cells, which express D2 receptor, are an exemplary model of hyperPRL derived from rat pituitary adenoma cells responsive to dopamine [12]. Dose-dependent and time-course responses of PRL secretion and synthesis to FMD treatment were evaluated in this cell line. $\mathrm{GH} 3$ cells were derived from rat pituitary lactotropic tumoral cells that lack D2 receptor expression [13,14], which were used to determine if deficiency of D2 receptors altered the suppression of FMD on hyperactive PRL. Consistent with D2- action, FMD did not affect
$\mathrm{PRL}$ in rat pituitary lactotropic tumor-derived $\mathrm{GH} 3$ cells that lack the D2 receptor expression. These studies revealed D2 receptor is necessary for anti-hyperPRL activity of FMD. PC12 cells from rat pheochromocytoma abundantly express D2 receptors and DAT $[15,16]$. FMD significantly increased the expression of D2 receptors and DAT in PC12 cells. Results suggested that D2 receptor and DAT all played important roles in anti-hyperPRL activity of FMD.

Dopamine receptors belong to the family of seven transmembrane domain G-protein coupled receptors (GPCR) [17-19]. Dopamine receptors D1 and D2 are classified into two subfamilies based on their differential effect on adenylyl cyclase.

Classically, the functions of dopamine receptors have been associated with the regulation of adenylate cyclase-protein kinase A through Gprotein-mediated signaling. Two classes of GPCR mediate dopamine functions, D1-like receptor subtypes (D1 and D5) couple mostly to $\mathrm{Ga}_{\mathrm{s}}$ and stimulate the production of the second messenger cyclic adenosine monophosphate

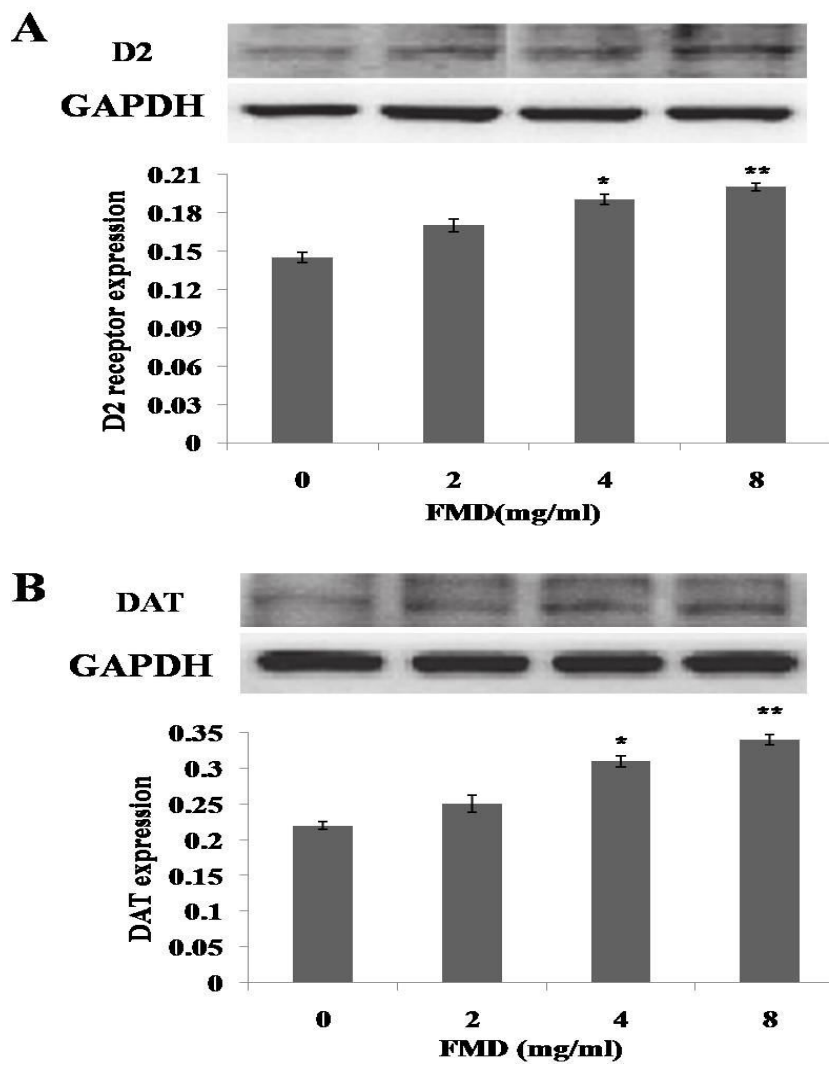

Fig 3: Effect of $24 \mathrm{~h}$ FMD treatment on the D2 receptor expressions (A) and DAT expressions (B). Data are expressed as mean \pm SEM $(n=4)$ and analyzed using one-way ANOVA. ${ }^{*} p<0.05$ and ${ }^{* *} p<0.01$ versus $0 \mathrm{mg} / \mathrm{ml}$ group 
(CAMP) and the activity of protein kinase $A$ (PKA). By contrast, D2-like subfamily (D2, D3 and D4) couple to $\mathrm{Ga}_{\mathrm{i} / \mathrm{o}}$ and regulate the production of cAMP thus resulting in a diminution of PKA activity [20-22]. The physiological and pathological roles of DR2 have been recognized in some organs such as brain and kidney [23,24]. In the adenohypophysis, the predominant dopamine receptor is the D2 receptor [25]. Transfection of the dopamine D2 receptor into a pituitary cell line results in a decrease in intracellular cAMP and inhibits prolactin secretion when dopamine is added to the cell culture [26]. Most conventional anti-hyperPRL agents reduce PRL secretion through D2 receptor in the hypothalamic neuroendocrine dopaminergic system. In our study, FMD inhibited PRL secretion via dopamine D2 receptor in MMQ cell. These suggest that FMD showed anti-hyperPRL activity via dopamine D2 receptor.

\section{CONCLUSION}

The findings of this study show that FMD inhibits PRL secretion in hyperPRL rats effectively. D2 receptor and DAT play important roles in the antihyperPRL activity of FMD.

\section{ACKNOWLEDGEMENT}

Ming-xia Li and Hong Liu contributed equally to this work.

\section{REFERENCES}

1. Lee DY, Oh KL, Yoon BK. Prevalence of hyperprolactinemia in adolescents and young women with menstruation-related problem. Am J Obstet Gynecol 2012; 206: e1- e5.

2. Biller BM, Luciano A, Crosignani PG. Guidelines for the diagnosis and treatment of hyperprolactinemia. $J$ Reprod Med.1999; 44: 1075-1084.

3. Greer Me, Moraczewski T, Rakoff JS. Prevalence of hyperprolactinemia in anovulatory women. Obstetr Gynecol. 1980; 56: 65-69.

4. Webster J, Piscitell G, Polli A. A comparison of cabergoline and bromocriptine in the treatment of hyperprolactinemic amenorrhea. N Engl J Med. 1994; 331: 904 - 909

5. Zhang ZJ, Tan $Q R$, Zhen XC, Tong Y. The potential benefits of herbal medicines for schizophrenia: from empirical observations to clinical trials (chapter 16). In: Hertzman M, Adler L, editors, Clinical Trials in Psychopharmacology. UK: Wiley-Blackwell; 2010; pp 311-335
6. Wei AH Cai YL Wu JH. The effect of malt extract on prolactin levels in HPRL mice. Herald Medicine 2009; 28: 1441-1443.

7. Zhou W, Zhang EJ, Gao TX. The study of malt extract on hyperprolactinemia. Hubei J Trad Chinese Med 2008; 30: 10-11.

8. Fitzgerald P, Dinan TG. Prolactin and dopamine:what is the connection? J Psychopharmacol 2008; 22(2S): 12-19.

9. Demaria JE, Nagy GM, Lerant AA, Fekete MI, Levenson $C W$, Freeman ME. Dopamine transporters participate in the physiological regulation of prolactin. Endocrinology 2000; 141: 366-374.

10. European Commission [homepage on the internet]. Directive 2010/63/EU on the protection of animals used for scientific purposes [cited 2013 Jan 16].Available

from:http://ec.europa.eu/environment/chemicals/lab Animals/legislation_en.htm.

11. Laszczyńska M, Slucz S, Piasecka M, Skowron J, Debiń T. Germ cells with nuclear DNA fragmentation related to apoptotic cells in rat testis in experimental hyperprolactinemia induced by metoclopramide. Folia Histochem Cytobiol 2002; 40: 163-164.

12. Judd AM, Login IS, Kovacs K, Ross PC, Spangelo BL, Jarvis WD. Characterization of the MMQ cell, a prolactin-secreting clonal cell line that is responsive to dopamine. Endocrinology 1988; 123: 2341-2350.

13. Giacomini D, Haedo M, Gerez J. Differential gene expression in models of pituitary prolactin-producing tumoral cells. Horm Res. 2009; 71(Suppl.2): 88-94.

14. Missale C, Castelletti L, Boroni F. Epidermal growth factor induces the functional expression of dopamine receptors in the GH3 cell line. Endocrinology 1991; 128: 13-20.

15. Chiasson K, Daoust B, Levesque D. Dopamine D2 agonists, bromocriptine and quinpirole, increase MPP+ -induced toxicity in PC12 cells. Neurotox Res. 2006; 10: 31-42.

16. Fazeli G, Olirg SN. The role of the dopamine transporter in dopamine-induced DNA damage.Brain Pathol. 2011; 21: 237-248.

17. Gingrich JA, Caron MG. Recent advances in the molecular biology of dopamine receptors, Annu. Rev. Neurosci. 1993; 16: 299-321.

18. Li HZ, Guo J, Gao J. Role of dopamine D2 receptors in ischemia/reperfusion-induced apoptosis of cultured neonatal rat cardiomyocytes. J. Biomed. Sci. 2011; 16(18): 18

19. Li HZ, Han LP, Jiang CM. Effect of dopamine receptor 1 on apoptosis of cultured neonatal rat cardiomyocytes in simulated ischaemia/reperfusion. Basic. Clin. Pharmacol. Toxicol. 2008; 102: 329-336.

20. Missale C. Dopamine receptors: from structure to function. Physiol. Rev. 1998; 78: 189-225. 21.

21. Greengard $P$. The neurobiology of slow synaptic transmission. Science 2001; 294: 1024-1030.

Trop J Pharm Res, February 2015; 14(2): 268 
22. Beaulieu JM, Gainetdinov RR, Caron MG. The Akt-GSK3 signaling cascade in the actions of dopamine. Trends. Pharmacol. Sci. 2007; 28: 166-172.

23. Madras BK. History of the discovery of the antipsychotic dopamine $d 2$ receptor: $A$ basis for the dopamine hypothesis of schizophrenia. J. Hist. Neurosci. 2013; 22: 62-78.

24. Narkar V, Kunduzova O, Hussain T. Dopamine D2-like receptor agonist bromocriptine protects against ischemia/reperfusion injury in rat kidney. Kidney Int. 2004; 66: 633-634.

25. Cronin MJ. The role and direct measurement of the dopamine receptor(s) in the anterior pituitary. In: Muller EE, MacLeod RM, Eds, Neuroendocrine perspectives 1982; 1: pp 169-210.

26. Nilsson C, Eriksson E. Partial dopamine D2 receptor agonists antagonize prolactin regulating $D 2$ receptors in a transfected clonal cell line (GH4ZR7). Eur $J$ Pharmacol 1992; 218: 205-211. 